\title{
FINANCIAL ADVICE AND INVESTOR PROTECTION: A COMPARATIVE OVERVIEW
}

\author{
Sandra Booysen ${ }^{1}$
}

\begin{tabular}{lllll}
\hline A. INTRODUCTION & 1.01 & & mitigation & 1.22 \\
1. Who to protect & 1.06 & C. A JURISDICTIONAL PERSPECTIVE & 1.23 \\
2. Robo-advice & 1.09 & $1 . \quad$ Merit versus disclosure regulation & 1.26 \\
B. THE ROLE OF PRIVATE LAW & 1.12 & 2. Remuneration of financial advisers & 1.31 \\
1. Tort law & 1.13 & 3. Regulatory Enforcement and Private & \\
2. Contract law & 1.16 & Dispute Resolution & 1.32 \\
3. Equity & 1.20 & D. CONCLUSION & 1.38 \\
4. Damages: causation, remoteness, & & & &
\end{tabular}

\section{A. INTRODUCTION}

1.01 Financial advisory or wealth management services have become increasingly accessible to the general public particularly since the $1990 \mathrm{~s},{ }^{2}$ and increased investment activity has inevitably led to a greater number of disputes between investors and financial advisers. Unsurprisingly, claims mushroom following market downturns, of which there is no better example than the 2007-9 global financial crisis (GFC). ${ }^{3}$ The GFC was preceded by a period of remarkable product innovation, including through securitisation, and heightened consumption of these products, amplified by the ease of cross-border transactions. ${ }^{4}$ Many investors no doubt made excellent returns, but the collapse of the markets in 2008 exposed many others to considerable losses. The losses sparked widespread and vocal dissatisfaction about the conduct of financial advisers

1 I thank Mercer Bullard, Keith Stanton, Helena Whalen-Bridge, Christian Witting and Alex Zhou for their comments.

2 See Dimity Kingsford Smith, 'Regulating investment risk: individuals and the Global Financial Crisis' (2009) 32:2 UNSWLJ 514, 518.

3 Other crises that underlie investor-adviser litigation include the Asian Financial Crisis of 1997 and the Russian Financial Crisis of 1998 .

4 Basel Committee on Banking Supervision 'The Joint Forum: Customer suitability in the retail sale of financial products and services' (Bank for International Settlements, April 2008) paras 26-28 <www.iosco.org/library/pubdocs/pdf/ IOSCOPD268.pdf> accessed 25 February 2021; Emine Boz and Enrique Mendoza 'Financial innovation, the discovery of risk, and the US credit crisis' (2014) 62 Journal of Monetary Economics 1, 2. 
and their perceived disregard for the interests of their customers, and prompted a debate about the adequacy of investor protection frameworks in many jurisdictions. The debate was aired in different settings, including the media, the courts, parliaments and academic scholarship, and the increased attention has subjected the financial advising industry to much scrutiny.

Since the GFC, concerns about the availability and quality of financial advice have arisen in other contexts. In the UK, for example, the mis-selling of payment protection insurance (PPI) came to a head in 2011..$^{5}$ UK lenders were accused of selling expensive PPI cover to people who didn't need it or couldn't afford it, and on terms that rendered the apparent protection an illusion. Tens of billions of pounds have been paid by the culprits in penalties and compensation payments. In Australia, a Royal Commission into misconduct in the financial services industry was launched in December 2017. Its final report from February 2019 is less than flattering about various aspects of the industry. ${ }^{6}$ It says, for example, that the history of the financial advising sector is one of an incomplete transformation - from an industry dedicated to the sale of financial products to a profession concerned with the provision of financial advice'. As this book is being finalised, the economic effects of the Covid-19 pandemic are being felt around the world. A deterioration in financial wellbeing is likely to adversely affect financial commitments, and may trigger fresh allegations of inadequate financial advice as dissatisfaction escalates.

It is, therefore, opportune to examine the subject of investor protection and the interests of its various stakeholders: investors, advisers, financial institutions, and society more broadly. In this chapter, I give an overview of the challenges faced in designing an investor protection framework and the many facets that need to be considered. These include how to respond to technology-driven developments, identifying who to protect, the role of private law rights versus regulation, the optimal regulatory tools, the need for active regulatory enforcement and providing access to effective private dispute resolution schemes. The discussion highlights features of the regulatory regimes in six significant financial jurisdictions: Australia, China, Hong Kong, Singapore, the UK and the US. The adequacy of an investor protection framework must be constantly reviewed to optimise the financial wellbeing of all stakeholders, strike appropriate balances between conflicting interests, and respond to the constant evolution of the financial sector.

Having regard to the architecture of investor protection frameworks, some jurisdictions have a body of law dedicated specifically to the financial advising industry, ${ }^{8}$ while others disperse financial advising regulation within a broader financial services regulatory framework. ${ }^{9}$ The

5 Financial Conduct Authority (FCA) 'Payment protection insurance explained' 22 August 2020 < www.fca.org.uk/ppi/ ppi-explained> accessed 25 February 2021.

6 See Kenneth M Hayne 'Final Report: Royal Commission into Misconduct in the Banking, Superannuation and Financial Services Industry' (Commonwealth of Australia 2019) <www.royalcommission.gov.au/sites/default/files/ 2019-02/fsrc-volume-1-final-report.pdf $>$ accessed 25 February 2021.

7 Ibid, 119. For similar observations about a sales culture in the industry, see Richard Samuel 'Banks, politics, and the financial crisis: a demand for culture change (Part 2)' 14 June 2016 OUPblog <https://blog-oup-com.libproxy1.nus.edu .sg/2016/06/banks-politics-finance-law-part-2/> accessed 21 February 2021.

8 See Singapore's Financial Advisers Act (Cap 110, 2007 Rev Ed Sing), and subsidiary regulation; see also Neo, ch 11.

9 China and Hong Kong are examples. Financial advising is regulated within a sectoral framework that has banking, securities and insurance at its core: see Zhou, ch 9, and Ding and Ho, ch 10. 
difference between the two approaches may be cosmetic, since the regulation of financial advising invariably operates in conjunction with other laws governing the issue and distribution of financial products, which tend to be found in legislation regulating companies, securities, futures and derivatives. A common, basic regulatory control is that financial advisers, whether corporate or individual, must be licensed or registered unless exempt. ${ }^{10}$ In that way minimum thresholds can be insisted on, for instance as to financial standing, sound character of senior staff and suitable qualifications. Licensing also brings financial advisers within the sights of the regulator for ongoing supervision and compliance purposes. Recommendations to buy or sell financial products are usually at the core of the numerous activities that a licensing regime seeks to capture.

1.05 Banks are prominent financial advisers in some jurisdictions, including Australia, the Hong Kong Special Administrative Region (Hong Kong), Singapore and the UK. Many high-profile investment disputes in the past 20 years, involving large sums of money, have concerned banks. The bank as a wealth management adviser adds another dimension to the multi-faceted bank-customer relationship. Basic banking services involve the provision of accounts that hold deposits and facilitate payment, as well as access to loan facilities. The extension into wealth management services has allowed banks to harness an intermediary vantage point which they occupy between their customer base and the financial institutions that issue and distribute investment products. ${ }^{11}$ At the same time, the legal framework governing the provision of ordinary account services has been influential in determining the rights and duties in the wealth management context, and has contributed to the limited ability of private law to offer investor protection, as discussed further below. ${ }^{12}$

\section{Who to protect}

1.06 A jurisdiction that is committed to establishing an investor protection regime has a number of design questions to decide - primarily who to protect and how, since investors differ, as do their needs. Many jurisdictions recognise a category of investors that deserve particular protection. They may be referred to as the retail, consumer or private investor, and can be contrasted with the professional institutional investor at the other end of the scale. The profile of persons deserving to fall into the retail category may vary considerably as regards financial means, knowledge and acumen, although the stereotypical image may be of a person with a distinctly vulnerable profile. Such investors undoubtedly exist, as shown by the Hong Kong case of Chang Pui Yin v Bank of Singapore Ltd (Chang Pui Yin), where the trial court described the investors as 'a simple couple who led uncomplicated lives'. ${ }^{13}$ Their combined work experience included the roles of primary school teacher, cashier, janitor and factory foreman; their investment monies were a gift from a wealthy relative, and at the time of making the investments they were in their 60s and 70s. The term 'retail investor' can also include professionals, such as the

10 See eg chs 8-13.

11 Eg Hong Kong, where investors complained about the marketing of complex products to banks' customer database following the collapse of Lehman Brothers: see Securities and Futures Commission 'Issues Raised by the Lehmans Minibonds Crisis: Report to the Financial Secretary', December 2008 para 4.2 <www.sfc.hk/sfc/doc/EN/general/ general/lehman/Review\%20Report/Review\%20Report.pdf> accessed 12 January 2021.

12 See also chs 4-6.

13 [2016] 5 HKC 329 (CFI) [4], on appeal [2017] 4 HKLRD 458 (CA) [1]. 
solicitor in Rubenstein v HSBC Bank Plc, whom the English High Court termed 'a retail client of medium sophistication'. ${ }^{14} \mathrm{Mr}$ Rubenstein's investment monies were the sale proceeds from the family home, which were being invested short-term pending the purchase of a new house. Jurisdictions may rightly recognise businesses as retail investors too, since their bargaining power is not necessarily stronger than that of the average individual, and business status is not aligned with investment acumen. ${ }^{15}$ In Crestsign Ltd $v$ National Westminster Bank plc, a corporate investor was described by the English High Court as 'a retail client and not a large and sophisticated commercial party'. ${ }^{16}$

Jurisdictions may differentiate between retail investors, and offer them varying degrees of protection. In the UK, for instance, a statutory tort for breach of the conduct rules is limited to a 'private person', which does not include businesses. ${ }^{17}$ Recourse to the UK's Financial Ombudsman service is also restricted - to private persons, small trusts, charities and businesses. ${ }^{18}$ In Singapore, 'accredited investors' do not enjoy all the statutory protections given to retail investors. ${ }^{19}$ This category of investors is identified with reference to financial means, not financial knowledge, which is considerably harder to assess. Financial means is perhaps an indicator of ability to bear risk, and it may often correlate with financial knowledge or capacity to understand, but a regulatory framework cannot assume that means and knowledge are synonymous. The potential gap in protection which could result from using means as a classification tool was addressed in Singapore by amendments in 2019 that made accreditation an opt-in, rather than a default, category. Investors in Singapore now need to consent in writing to being classified as 'accredited' after the significance of the classification has been made clear to them. ${ }^{20}$

Unfortunately, a system of classifying investors does not necessarily cure the problem it seeks to address. Investors that agree to or seek a more sophisticated classification may be suffering from one or more of the well-documented investor biases. ${ }^{21}$ They are, for example, likely to be more focused on the potential for gains than losses, and to desire access to a greater range of products than a retail classification permits. As a result, they may push for a classification that gives them access to riskier products, thereby sacrificing some of the available protections.

\section{Robo-advice}

Robo- or digital advice is a new frontier in the delivery of financial services. It uses digital platforms programmed with algorithms to make financial advice more accessible to the retail investor, both in terms of cost and minimum investment sums. Robo-advice is one way of

14 [2011] 2 CLC 459 (QB) [15], on appeal [2012] EWCA Civ 1184 (CA).

15 See eg Holly Powley and Keith Stanton 'SMEs and financial services disputes: Part 1: the Ombudsman' (2019) 2 JIBFL $89,89$.

16 [2015] 2 All ER (Comm) 133 [115].

17 Financial Services and Markets Act 2000 (UK) s 138D(2) read with Financial Services and Markets Act 2000 (Rights of Action) Regulations 2001 (ROA) reg 3(1).

18 Financial Services and Markets Act 2000 (UK) s 226(2); FCA 'Dispute Resolution: Complaints' (FCA Handbook) DISP 2.7 <www.handbook.fca.org.uk/handbook/DISP.pdf> accessed 27 February 2021.

19 Financial Advisers Regulations, Rg 33 (GN No S462/2002, 2004 Rev Ed Sing).

20 Securities and Futures (Classes of Investors) Regulations 2018 (GN No S665/2018, Sing) reg 3.

21 See eg Clara Martins Pereira 'Reviewing the literature on behavioural economics' (2016) 11:3 CMLJ 414; Smith (n 1) 531. 
advancing the enhanced financial inclusion agenda now embraced in many jurisdictions. This agenda looks beyond mere bank account access and seeks to enhance financial wellbeing through the optimal use of bank accounts. ${ }^{22}$ One dimension of financial wellbeing is financial planning, and it is a concern that many consumers never seek financial advice. ${ }^{23}$ In Hong Kong, a 2017 study of retail investor perceptions and habits offers valuable insight into the sector. ${ }^{24}$ The study indicated, for example, that the share market is the most popular investment outlet for retail investors, followed by foreign exchange and investment funds; that 86 per cent of retail investors relied mainly on information from family and friends for their stock market investment decisions; and that online platforms were the most popular channels used to access the stock market. ${ }^{25}$ It is encouraging that a high percentage of Hong Kong's retail investors perceived derivatives and structured products as being high risk; ${ }^{26}$ on the other hand, the investors surveyed showed little interest in issues relating to corporate governance, and few exercised their right to vote in listed company meetings. ${ }^{27}$

1.10 Robo-advising has risen to prominence since the GFC as a complement to the more traditional human adviser. As a disruptive technology, ${ }^{28}$ it is a relatively unfamiliar but potentially beneficial phenomenon which adds an additional layer of complexity to the challenges facing regulators in devising an appropriate regulatory framework. The discussion by Yaru Chia in Chapter 2 considers the use of regulatory sandboxes to foster the development of robo-advisory business models, and discusses how five jurisdictions (Australia, Hong Kong, Singapore, the UK and the US) are regulating robo-advisers. Chia's comparative analysis shows that robo-advisers operate within the same regulatory framework as human advisers. For example, the ubiquitous requirements of disclosure and suitability apply with the same force to this medium as they do to human advisers. It is also striking that regulators have favoured the use of soft law to guide robo-advisers in meeting regulatory expectations. Soft law is more flexible and can set goals without stifling a business model that is still in its start-up phase. At the same time, soft law is less certain, and gives rise to questions about enforceability.

22 See eg Ravi Menon 'Financial Inclusion and Innovation: Retaining the Customer' (Opening Remarks by Managing Director, Monetary Authority of Singapore, at the Bank for International Settlements - World Bank Roundtable on Impact of Technology on Financial Inclusion and Financial Stability, at SFF x SWITCH 2019 on 13 November 2019) <www.mas.gov.sg/news/speeches/2019/financial-inclusion-and-innovation-retaining-the-customer> (accessed 25 February 2021).

23 See Jill Fisch, Marion Labouré, and John Turner 'The Emergence of the Robo-Advisor' in Julie Agnew and Olivia Mitchell (eds) The Disruptive Impact of FinTech on Retirement Systems (2019, OUP) ch 2, 18; BlackRock 'Digital Investment Advice: Robo Advisors Come of Age' (BlackRock, September 2016) 3 <www.blackrock.com/corporate/ literature/whitepaper/viewpoint-digital-investment-advice-september-2016.pdf> accessed 25 January 2021; Australian Securities and Investments Commission (ASIC) 'Australian Investors: At a Glance' (Report 121, April 2008) 31 <https://download.asic.gov.au/media/1344854/rep_121_Australian_investors_at_a_glance.pdf> accessed 25 February 2021.

24 Investor Education Centre 'Retail Investor Study (Research Report, December 2017) <www.ifec.org.hk/common/pdf/ about_iec/IEC-Retail-Investor-Study-report.pdf> accessed 20 February 2021.

25 ibid 3-4.

26 ibid 3.

27 ibid 5.

28 See Iris H-Y Chiu, 'Fintech and disruptive business models in financial products, intermediation and markets: policy implications for financial regulators' (2016) 21 J Tech L \& Pol'y 55. 
Robo-advice facilitates the delivery of accessible financial advice, which is a reason to support Chia's argument that regulation should be used sensitively to allow it to develop prudently and respond to the needs of the small retail investor. She argues that the robo-medium also offers opportunities to address the conflict of interest problems that can arise in financial advising, and to counteract the investor biases which may lead to irrational investment decisions. A more recent development that highlights the value of robo-advisory services is the Covid-19 pandemic, which resulted in widespread lockdowns starting in 2020, forcing people to manage their finances from their homes. Digital financial services have unsurprisingly seen heightened demand since $2020 .{ }^{29}$

\section{B. THE ROLE OF PRIVATE LAW}

A distinct trend in retail investor protection is the intensification of regulatory requirements, ${ }^{30}$ including both hard and soft law measures. These measures play a prominent, indeed dominant, role in many jurisdictions. ${ }^{31}$ It is important to remember, though, that such a framework operates against the background of the pre-existing law, which remains relevant particularly when the criteria for statutory protection are not met - for example, by small to medium enterprises (SMEs) and individuals who have elected not to be classified as retail investors in order to access investment products with potentially higher returns. For that reason, the response of the private law to the problem of flawed investment advice remains relevant. In the chapter on the investor protection framework in China, the only civil law jurisdiction covered in the volume, ${ }^{32}$ Alex Zhou notes that the Chinese Civil Code and the Chinese Consumer Protection law generally offer protections for the consumers of goods and services. ${ }^{33} \mathrm{In}$ common law systems the main bodies of private law that have the potential to remedy flawed investment advice are tort, contract and equity. However, these systems face challenges in fulfilling their remedial function, which explains why more targeted regulatory intervention is so prominent in this domain. The challenges are considered here with reference primarily to four common law jurisdictions: Australia, Hong Kong, Singapore and the UK.

\section{Tort law}

Tort law is directed at a wide range of conduct that is considered harmful, but in most instances does not constitute a crime. The most significant tort in the financial advisory context is the tort of negligence, based on a duty of care. It is measured by the standard of a reasonable person, in this instance the reasonable financial adviser. It is uncontroversial that the duty of care tort

29 See eg FCA, 'Regulatory Sandbox - Cohort 6' (published 23 July 2020, updated 14 October 2020) <www.fca.org.uk/ firms/regulatory-sandbox/regulatory-sandbox-cohort-6> accessed 26 February 2021.

30 Many measures were prompted by the GFC. However, Bullard, ch 13, notes that the main regulatory response to the GFC in the US (the Dodd-Frank Act) showed little concern for investor protection; in China, where investor protection is receiving growing regulatory attention, it may be more of a response to the growth in the sector than to the GFC.

31 As argued by Stanton, ch 12; but see Bullard, ch 13 on public versus private enforcement in the US. See also Iris Chiu and Alan Brener 'Articulating the gaps in financial consumer protection and policy choices for the financial conduct authority: moving beyond the question' (2019) 14:2 CMLJ 217.

32 The UK framework has, however, been heavily influenced by directives emanating from the European Union, which includes many civil law jurisdictions.

33 Zhou, ch 9. 
serves to compensate for harm caused by wrongful conduct. A view advanced by Christian Witting in Chapter 3 is that tort law also serves to deter, and that courts play a regulatory function when they apply tort law. He argues that tort law is able to fulfil a deterrent function in the financial services industry by virtue of the corporate or other organisational structures through which financial services tend to be delivered, structures which can be used to shape future conduct. This deterrent or regulatory view of tort law offers a valuable perspective in the financial services environment, where the ascendancy of regulatory law is marginalising the role of private law. Witting's point is not to challenge the undoubted efficacy of focused regulatory rules, but to emphasise the complementary role that private law, particularly tort law, can and does play when it gets the opportunity.

1.14 There is, however, a significant caveat to the argument that tort law can play a regulatory function in the wealth management sector. Financial services are rendered pursuant to agreements which set out the rights, duties, risks and liabilities of the parties. In other words, contracts also play a regulatory role, albeit in a private, consensual sense. The extensive use of contract terms can marginalise the role of tort in some jurisdictions. The terms are drafted by the service providers, and tend to be populated with provisions which seek to preclude civil recourse, whether in tort, contract or equity. ${ }^{34}$ The ironic effect can be that a contract seemingly to advise on investments or financial planning may not include a promise to advise, and may restrict the role of the adviser to providing information. As a result, any duty of care which might ordinarily arise in tort may be incompatible with the clear terms of the contract.

1.15 Freedom of contract is such a strong value in the common law that even statutory attempts to moderate the use of these terms may struggle to find traction ${ }^{35}$ - as seen in Hong Kong, Singapore and the UK, which share a legislative enactment, the Unfair Contract Terms Act (UCTA). ${ }^{36}$ The problem has been less prevalent in Australia and the US, both of which have kept freedom of contract on a shorter leash through different legislative controls. ${ }^{37}$ Here, Witting reminds us of the discussion in the seminal UK tort case of Henderson $v$ Merrett Syndicates Ltd regarding concurrent liability in tort and contract. ${ }^{38}$ The case signalled the primacy of tort law as an imposed legal framework within which contracts are made, although the House of Lords accepted that tort duties can be displaced by agreement when the parties have clearly agreed to do so. ${ }^{39}$ Contract's objective approach to ascertaining consent, in particular in the form of a signature, means that such clear agreement is relatively easy to establish.

\section{Contract law}

1.16 The powerful effect of contract terms is one of the reasons for the use of regulatory rules to provide retail investor protection, but despite the importance of these rules, actionable rights at

34 See Booysen, ch 4; McMeel, ch 6.

35 See Beale and Palmer, ch 5, also Sandra Booysen, 'Twenty years (and more) of controlling unfair contract terms in Singapore' [2016] SJLS 219.

36 The Unfair Contract Terms Act 1977 is a UK statute that was adopted in slightly modified terms in Hong Kong: Control of Exemption Clauses Ordinance (Cap 71) and Singapore: Unfair Contract Terms Act (Cap 396, 1994 Revised Edition).

37 See Paterson, ch 8 and Bullard, ch 13.

38 [1995] 2 AC 145 (HL).

39 ibid 194-5. 
common law remain important. As noted earlier, regulatory frameworks may not be targeted equally at all investors, particularly more sophisticated individuals and businesses. ${ }^{40}$ In my discussion of the duty to advise in Chapter 4, I argue that it would be unfortunate if the common law could not achieve fair outcomes and had to abdicate that responsibility to statute. Put differently, the ability of private law to deal with impediments to its fair operation is important notwithstanding that regulation may be effective in controlling the behaviour of investment advisers. As regards the duty to advise, I suggest that the common law empowers itself to respond to the need currently being met mainly by regulation, by recognising that retail investors in a contract for wealth management services expect to receive advice, and any terms to the contrary must be rigorously subjected to the contractual fairness regime that pertains in each jurisdiction. Notions of fairness or reasonableness are informed by the sense of fair play that each jurisdiction embraces, and need to take account of both the contractual process, such as proper disclosure of contract terms and the absence of duress, as well as its substantive fairness.

Two clauses that have achieved notoriety for their operation in contracts between investors and financial advisers are entire agreement clauses (EACs) and non-reliance clauses (NRCs). Their exact effect depends on their drafting, but basically EACs seek to preclude the operation of oral promises, such as promises to advise, while NRCs seek to preclude an actionable misrepresentation from arising, for example a statement that an investment product is low risk. Much has been written about this duo in the financial advisory context and their operation through the controversial doctrine known as contractual estoppel. In Chapter 5, Hugh Beale and Georgia Palmer examine the debate and conclude that the culture of freedom of contract, which is at the heart of the doctrine of contractual estoppel, remains a strong one in a number of jurisdictions. They contrast the legislative approach in Australia, where EACs, NRCs and contractual estoppel have not taken hold. ${ }^{41}$

As Beale and Palmer point out, most of the cases in which EACs and NRCs have been effective have not involved the most vulnerable retail investors - such as the elderly couple, the Changs, in the Hong Kong case mentioned earlier. These cases tend to be resolved outside of the formal court system, for example by an Ombudsman service or small claims tribunal, and in this context the regulatory system may disallow or discourage such one-sided contract terms. ${ }^{42}$ If the problem is substantial enough a tailored solution may be found, as happened in Hong Kong and Singapore following the collapse of Lehman Brothers in 2008. Leading up to the GFC, large numbers of retail investors were inappropriately sold complex investment products in a handful of jurisdictions, including Hong Kong and Singapore. ${ }^{43}$ Because of the scale of

40 As illustrated in the UK by Crestsign (n 16) [13]; Thornbridge Ltd v Barclays Bank Plc [2016] All ER (D) 16 (Jan) (QB) [138]-[141]. See also Stanton, ch 12. A customer may also be forced to rely on the common law where the limitation period for the statutory rights is shorter: see Keith Stanton, 'Investment advice: the statutory remedy' (2017) 33:2 J Prof Neg 153, 169.

41 See Barnett, ch 7, Paterson, ch 8.

42 An example from Hong Kong is the Code of Conduct for Persons Licensed by or Registered with the Securities and Futures Commission (27th edn, December 2020) para 6.5 <www.sfc.hk/-/media/EN/assets/components/codes/ files-current/web/codes/code-of-conduct-for-persons-licensed-by-or-registered-with-the-securities-and-futures -commission/Code_of_conduct-Dec-2020_Eng.pdf> accessed 13 January 2021 which disapproves of the use of non-reliance clauses.

43 See Hans Tjio, 'Challenges to Singapore from the Global Financial Crisis: actual and suggested legal and regulatory reponses' [2013] 1 SJLS 168, 172. 
the problem, a bespoke response was needed. After prompting from the financial regulators, widespread voluntary settlements were made by the financial advisers involved, mostly banks. ${ }^{44}$

1.19 In the event that cases involving particularly vulnerable investors are litigated today, courts are likely to deploy the available common law and legislative tools to limit the operation of EACs and NRCs as appropriate. ${ }^{45}$ At the other end of the scale, institutional investors are likely to be bound by them - and understandably so, given their expertise, awareness, access to advice and bargaining power. The area of controversy, where the brunt of EACs, NRCs and similar clauses are borne, is between these two groups, namely investors not classified as retail but lacking the investment skill and financial substance of institutional investors. It is here that different views may be taken of the adequacy of the available controls, in particular jurisdictions on contractual freedom, and the utilisation of those controls.

\section{Equity}

1.20 A third pillar of private law that potentially has a role to play in determining rights, duties and remedies in a wealth management relationship is equity, in particular fiduciary duties. There can be different conceptions of fiduciary duties but at their core they tend to be founded on the idea of loyalty requiring the fiduciary to act in the interests of another and avoid conflicts of interest. ${ }^{46}$ Fiduciary duties have considerable potential to affect financial advisers, bearing in mind the likelihood of reliance and fee models based on commissions, or profits on the sale of products acquired in bulk. Jurisdictions take different views on whether financial advisers are fiduciaries. English law has long resisted the idea that banks are fiduciaries. In 1848 the House of Lords decided that when a bank receives a deposit from a customer, it does so as a borrower, not as a fiduciary. ${ }^{47}$ This view has persisted even when the bank acts in other roles, including financial adviser, and it has been reiterated on numerous occasions. ${ }^{48}$

1.21 In Chapter 6, Gerard McMeel argues in favour of fiduciary or similar obligations for banks acting as financial advisers. He draws support for his argument from the policy stance reflected in regulatory rules, for example the best interests rule. ${ }^{49}$ Once again, a major impediment to the recognition of fiduciary duties is the fact that the relationship between the adviser and the investor is contractual, and the contract terms may not be consistent with a fiduciary relation-

See Hong Kong: SFC 'SFC, HKMA and 16 Banks Reach Agreement on Minibonds' (22 July 2009) <www.sfc.hk/ edistributionWeb/gateway/EN/news-and-announcements/news/doc?refNo=09PR100> accessed 26 February 2021; Singapore: Monetary Authority of Singapore 'MAS Releases Investigation Findings on the Sale and Marketing of Structured Notes Linked to Lehman Brothers' (7 July 2009) <www.mas.gov.sg/news/media-releases/2009/mas -releases-investigation-findings-on-the-sale-and-marketing-of-structured-notes-linked-to-lehman-brothers $>$ accessed 26 February 2021.

45 See eg Chang Pui Yin (n 13); Als Memasa v UBS AG [2012] 4 SLR 992 (CA) at [29]; Lee Chee Wei v Tan Hor Peow Victor [2007] 3 SLR(R) 537 (CA) [36]-[39].

46 See the frequently cited Bristol and West Building Society v Mothew [1998] 1 Ch 1, 18. See also Chiu and Brener (n 31) 230-3 on the differences between the UK and US conceptions of fiduciary duties in the financial context.

47 Foley v Hill (1848) 2 HL Cas 28.

48 See the discussion in EP Ellinger, E Lomnicka and CVM Hare Modern Banking Law (2011, OUP, 5th ed) 129. For a recent Singapore case, see AL Shams Global Ltd v BNP Paribas [2019] 3 SLR 1189 (HC) at [54].

49 See also Elizabeth Corcoran 'Fiduciary duties and financial services providers' (2020) 63 Irish Jurist 1; Ruth Plato-Shinar 'Law and ethics: the bank's fiduciary duty towards retail customers' in Costanza A Russo, Rosa M Lastra and William Blair Research Handbook on Law and Ethics in Banking and Finance (2019, Edward Elgar Publishing) ch 10214. 
ship, in particular an agreement by the adviser to selflessly pursue the investor's interests. To the contrary, the contract may expressly disclaim fiduciary obligations. McMeel criticises an approach which gives pre-eminence to such contract terms to determine fiduciary status, and supports a more policy-driven approach. In the US, by contrast, the fiduciary status of financial advisers is well established, although the existence and significance of the duty varies depending on the status of the adviser and the stance of the relevant regulator. ${ }^{50}$ Exclusion of the US fiduciary duty through contract terms is generally not tolerated by US legislation, but the duty can be watered down by giving disclosure, for example, of a conflict of interests.

\section{Damages: causation, remoteness, mitigation}

The discussion so far shows that a cause of action in tort, contract or equity can be hard to mount in the face of well-drafted contract terms to the contrary. Difficulties in proving other elements of these claims compound the problem. Financial markets are known to be volatile, ${ }^{51}$ and an investor seeking to hold a financial adviser liable for investment losses faces significant additional hurdles, as discussed by Katy Barnett in Chapter 7. These hurdles are the need to prove that the breaching conduct caused quantifiable loss that was not too remote, and that the losses were adequately mitigated. The requisite causal connection varies depending on the cause of action, ${ }^{52}$ with 'but-for' causation applying for common law claims in contract or tort, and 'a cause' for the less likely claims of fraudulent misrepresentation or breach of fiduciary duty. Barnett emphasises the need to keep causation questions and remoteness questions apart. Remoteness is a more normative concept that reflects the view that a defendant should not be liable for all the consequences that result from a wrong, particularly unusual consequences. In tort, remoteness is basically determined by the foreseeable losses at the time the tort was committed, and in contract it is determined by what losses were contemplated at the time of contracting. When losses result from a downturn caused by an out-of-the-ordinary occurrence, such as the GFC, causation and remoteness become more contentious. ${ }^{53}$ Looking ahead, Barnett flags the likelihood that claims related to the Covid-19 pandemic will raise difficult causation and remoteness issues.

\section{A JURISDICTIONAL PERSPECTIVE}

In developing their legal frameworks, jurisdictions learn from each other, which leads to similarities. Widespread adoption of certain features may reflect current best practices. At the same time, the precise implementation of accepted tools tends to vary between jurisdictions and offers an opportunity to compare and evaluate optimal strategies. Invariably, jurisdictions also have unique features that may respond to particular problems. For that reason, a comparative study of investor protection frameworks constructively informs the debate.

50 The US financial advising sector is fragmented: see Bullard, ch 13.

51 Stafford v Conti Commodity Services Ltd [1981] 1 All ER 691; OCBC Securities Pte Ltd v Yeo Siew Huan [1998] 1 SLR(R) $481[40]$.

52 See Barnett, ch 7.

53 See eg Rubenstein HC (n 14) [57]. 
1.24 The frameworks of six significant financial jurisdictions are discussed in this volume: Australia, ${ }^{54}$ the People's Republic of China (China), ${ }^{55}$ Hong Kong, ${ }^{56}$ Singapore, ${ }^{57}$ the UK ${ }^{58}$ and the US. ${ }^{59}$ While there is much common ground, each offers a distinct narrative on investor protection and strategies to achieving it. Australia was not untouched by the GFC, but it did not experience the level of investor losses seen in some of the other jurisdictions. It has a strong consumer protection culture, including a far-reaching statutory prohibition on misleading conduct. Despite its close historical ties with English law, the contractual estoppel doctrine and the associated EACs and NRCs have not taken hold. China's economic significance means that its approach to investor protection merits inclusion in a discussion of this topic. China was largely an onlooker during the GFC, in the sense that its financial institutions and population had limited direct exposure to the institutions that failed in the West. ${ }^{60}$ However, economic liberalisation has brought prosperity to the Chinese people and has led to a mushrooming of the investment sector. As a result, lawmakers are grappling with the need for increased investor protection measures.

1.25 The remaining four jurisdictions host major financial centres. Hong Kong and Singapore experienced the GFC in similar ways. Neither experienced the institutional collapses or had to resort to the bailouts seen in the US and UK; the extensive government guarantees of deposits that were put in place in both jurisdictions from October 2008 to December 2010 were not called upon. ${ }^{61}$ The GFC was, however, keenly felt by the investing public who held products linked to the failed institutions, which prompted public outcries followed by the settlements referred to earlier. Of the jurisdictions featured here, the UK and US were affected by the GFC most directly. The UK's extensive financial advising regulatory regime is an expression of EU law, one of the most significant economic regions in the world, and many of the measures adopted in this region have been echoed to some extent in other jurisdictions. The US has a large and complex financial industry. Regulation is dispersed among different sectoral and state regulators, and varies according to the status of the adviser and the assets advised on. In this respect, there are similarities between the US and China. The US was at the epicentre of the GFC and, alongside failing institutions, US investors were also affected. Claims were handled in different ways, including private arbitration, class actions and regulator-prompted settlements.

54 See Paterson, ch 8.

55 See Zhou, ch 9.

56 See Ding and Ho, ch 10.

57 Neo, ch 11.

58 See Stanton, ch 12.

59 See Bullard, ch 13.

60 See Robin Hui Huang, 'The regulation of securities offerings in China: reconsidering the merit review element in light of the Global Financial Crisis' (2011) 41:1 HKLJ 261, 282.

61 See Hong Kong: Hong Kong Monetary Authority ‘Commencement of the Enhanced Deposit Protection Scheme’ (Press Releases, 30 December 2010) <www.hkma.gov.hk/eng/news-and-media/press-releases/2010/12/20101230-4/\#: :text= The\%20Full\%20Deposit\%20Guarantee\%20provided,until\%20the\%20end\%20of\%202010> accessed 21 February 2021; Singapore: Lim Hng Kiang 'Impact of current issues to Asia's growth and the global environment ahead' (Ministerial Statement, 21 October 2008) <www.bis.org/review/r081023e.pdf> accessed 21 February 2021. 


\section{Merit versus disclosure regulation}

Two main approaches to investor protection are evident: merit and disclosure. In reality, jurisdictions tend to have elements of both, although one tends to dominate. There has been a renewed interest in merit regulation since the GFC, while the disclosure model has seen refinements. Merit regulation scrutinises investment products and determines or recommends for whom they are suitable. It might disallow some products completely or put them beyond the reach of certain investors. Merit regulation is criticised for being paternalistic, undermining autonomy, increasing moral hazard, putting too much burden on the regulator, and being a blunt tool, since suitability is a relative concept. On the other hand, the bounded rationality of retail investors can be used to justify a merit approach. ${ }^{62}$ China's wealth management regulations have distinct merit features; this has been defended as appropriate for the still-emerging Chinese investor market. ${ }^{63}$

Disclosure regulation reflects the philosophy that investors must make their own investment decisions, and it provides them with the information to do so having regard to their financial circumstances, needs and risk appetite. It is criticised for assuming too much about the capacity and inclination of investors to evaluate disclosures,${ }^{64}$ and for leading to an overload of information that cannot realistically be processed. ${ }^{65}$ Disclosure was the mantra in free-market jurisdictions leading up to the GFC, and remains prevalent. Hong Kong strongly defended its disclosure system in 2009, arguing that merit is a relative concept that can be determined only in relation to individual investors. ${ }^{66}$ Singapore had a merit-based system but largely moved to a disclosure system in 1999. ${ }^{67}$ Like Hong Kong, the UK has long embraced the disclosure philosophy. At the federal level in the US, the system is strongly disclosure-based, but it operates in conjunction with the fiduciary principle. ${ }^{68}$ At the state level, merit regulation is evident. ${ }^{69}$

Disclosure requirements insist on accuracy of information at a minimum, and all the jurisdictions considered here have laws against misleading statements by financial intermediaries, including financial advisers, ${ }^{70}$ over and above more general laws against fraud and misstate-

62 See Pereira (n 21).

63 See Huang (n 60).

64 See eg Asta Zokaityte 'Financial literacy and numeracy of consumers and retail investors' (2016) 11:3 CMLJ 405.

65 See eg ASIC Report 121 (n 23) 6. Accusations of over-disclosure and technical disclosure were made in regard to Lehman Brothers products sold to retail investors in Hong Kong and Singapore, see Hong Kong: Securities and Futures Commission 'Issues Raised by the Lehmans Minibonds Crisis: Report to the Financial Secretary', December 2008, paras 2.1, 4.3.5 <www.sfc.hk/sfc/doc/EN/general/general/lehman/Review\%20Report/Review\%20Report.pdf> accessed 25 February 2021; Singapore: 'Disclosure: quality counts, not just quantity' Business Times (Editorial, 26 February 2010).

66 SFC Report (December 2008) (n 65) paras 8.3, 24.4.

67 See Second Reading of the Securities and Futures Bill (2001), Singapore Parliament Reports Service, 5 October 2001, vol 73, Col 2127-28 (Deputy Prime Minister Lee Hsien Loong); also Hans Tjio (n 43) 176.

68 See Bullard, ch 13.

69 See Ronald J Columbo 'Merit regulation via the Suitability Rules' (2013) 12 J Int Bus \& Law 6-9.

70 Eg Australia: Australian Securities and Investments Commission Act 2001, s 12DB; China: Interim Procedures on Administration of Securities and Futures Investment Consultancy Consultancy (Zhengquan Qihuo Touzi Zixun Guanli Zanxing Banfa), issued by the Securities Commission of the State Council on 25 December 1997, effective 1 April 1998, arts 24(6), 25; Hong Kong: Securities and Futures Ordinance (Cap 571) ss 107-108; Singapore: Financial Advisers Act (n 8) s 26; UK: FCA 'Principles for Business' (FCA Handbook) PRIN 2.1, FCA Conduct of Business Sourcebook (FCA Handbook) COBS 4.2.1(1)R; US: 15 USC. § 80b-6, 15 US Code § 78j (2020); 17 CFR § 240.10b-5(2020). 
ment. An effective disclosure regime must, however, go beyond accuracy and encompass a duty to furnish adequate information to investors. Emphasis is increasingly being placed on salient disclosure in accessible language, since technical and over-disclosure can be as problematic as under-disclosure.

1.29 Today's merit regulation has been re-engineered away from the traditional 'regulator as gatekeeper' model, and manifests now in the widespread suitability and related requirements that apply to financial advisers and product issuers. All the jurisdictions discussed here have a version of the suitability rule, which requires investment recommendations to be suitable or appropriate for the customer. ${ }^{71}$ The suitability rule means that financial advisers must be adequately trained, they must be informed about the financial markets and available products, and they must be familiar with their customers' financial and other circumstances, called the know-your-customer (KYC) requirements.

1.30 Product issuers may also find themselves under suitability obligations which go beyond the historical disclosure requirements in prospectuses for share and debenture issues. In Australia, measures introduced in 2019 require issuers of financial products to specify the appropriate market for the product, and procure distribution accordingly. ${ }^{72}$ In this regard, Jeannie Paterson draws parallels in Chapter 8 with the safety obligations imposed on the manufacturers of goods. ${ }^{73}$ Hong Kong introduced a product approval process in 2014 that requires the providers of certain products to assess the fairness of the product and to certify that they have done so before the regulator will authorise the product. ${ }^{74}$

\section{Remuneration of financial advisers}

1.31 The remuneration model of financial advisers has received particular scrutiny. It has been criticised for giving perverse incentives and creating conflicts of interest through, for example, commissions, profits on product sales and interest on loan facilities. ${ }^{75}$ Fee and other incentive-based rewards received attention, for example, in the Australian Royal Commission Final Report, ${ }^{76}$

71 See Australia: Corporations Act 2001 s 961G; China: Interim Provisions on the Securities Investment Advisor Business, (Zhengquan Touzi Guwen Yewu Zanxing Guiding), first promulgated by the China Securities Regulatory Commission on 12 October 2010, amended 20 March 2020, effective 20 March 2020, art 11; Hong Kong: Code of Conduct for Persons Licensed by or Registered with the Securities and Futures Commission, para 5.2; Singapore: Financial Advisers Act (n 8), s 27(1), supplemented by MAS Notice on Recommendations on Investment Products (FAA-N16); UK: FCA Principles for Business (n 70) PRIN 2.1.1R(9); FCA Conduct of Business Sourcebook (n 70) COBS 9A; US: FINRA 'FINRA Rules' (FINRA) r 2111. See also Gail Pearson, 'Reading suitability against fitness for purpose - the evolution of a rule' (2010) 32 Sydney Law Review 273.

72 Corporations Act (n 71), ss 994B, 994E; see also Singapore: Securities and Futures Act (Cap 289, 2006 Revised edition Sing), s 309B.

73 See Paterson, ch 8.

74 SFC 'Circular to Product Providers of SFC-authorized unit trusts and mutual funds, SFC-authorized investment-linked assurance schemes and SFC-authorized unlisted structured investment products: Guidance on Internal Product Approval Process', (SFC March 2016) para 7, <https://apps.sfc.hk/edistributionWeb/gateway/EN/circular/doc? refNo= 16EC11> accessed 25 February 2021.

75 For case references to the remuneration structure, see Valse Holdings S.A v Merrill Lynch International Bank Ltd [2004] EWHC 2471 at [51]; JP Morgan Chase Bank v Springwell Navigation Corporation [2008] EWHC 1186 (Comm) at [436-437]; Bank Leumi (UK) plc v Linda Joy Wachner [2011] 1 CLC 454, at [53]; Rubenstein CA (n 14) [12].

76 Hayne (n 6) 26-7. 
while Mercer Bullard points out in Chapter 13 that large numbers of regulatory enforcement actions in the US concern investment recommendations motivated by higher fee yields for the adviser. The suitability rule helps to combat some remuneration conflicts of interest. Some jurisdictions have gone further and banned commission payments ${ }^{77}$ or subjected them to tighter controls, ${ }^{78}$ and there is an increased awareness of conflicts of interest - for example, when an adviser goes beyond making a recommendation and sells the product as well. This practice was prevalent in banks prior to the GFC which acquired products in bulk from issuers and sold them as principals to their customers, thereby creating the temptation to recommend these products over others.

\section{Regulatory Enforcement and Private Dispute Resolution}

Efficient regulatory enforcement and adequate, accessible private dispute resolution avenues are essential for an investor protection framework to be effective. Breach of regulatory rules may constitute an offence, attract a civil penalty or allow the regulator to sanction the conduct in some other way, for instance by restricting or removing a licence. On their own, such provisions are meaningless; what matters is the level of enforcement by the regulator. Keith Stanton's discussion in Chapter 12 reveals an active enforcement agenda on the part of the Financial Conduct Authority. He argues that regulatory enforcement against financial intermediaries in the UK has been, and will continue to be, more effective in protecting investors than private recourse. Bullard's US chapter highlights different combinations of regulatory enforcement and private actions in the US, depending on the sector. ${ }^{79}$ His discussion depicts a complex but overall reasonably effective system that is driven in part by competition between different regulatory bodies. On the other hand, Zhou notes in Chapter 9 that China's securities sector has been criticised for being weak on enforcement, although he points to actions taken since 2018 which suggest a more proactive enforcement agenda. ${ }^{80}$

In the absence of an explicit provision, statutory duties may not give rise to privately enforceable rights of action. ${ }^{81} \mathrm{~A}$ striking trend in investor protection reforms has been the creation of private rights to seek recourse for breaches of key statutory duties. Hong Kong gives a privately enforceable right for statutory misrepresentation leading to the acquisition or sale of securities or structured products, ${ }^{82}$ while in Singapore and the UK the statutory duties of disclosure and suitability confer rights of private enforcement. ${ }^{83}$ Such express statutory rights tend to complement intervention by the regulator which is not within the control of individual investors and may not facilitate the recovery of individual losses. The privately enforceable statutory rights offer an alternative to claims based on private law causes of action in tort or contract, which may be hard to prove. That said, they still require private action and the question must be asked: How effective is private enforcement as a mechanism to hold an industry to account? Taking

78 See Singapore: Financial Advisers (Remuneration) Regulations 2015 (GN No S 816).

79 Bullard ch 13.

80 Zhou, ch 9.

81 See eg Davis v Radcliffe [1990] 1 WLR 821 (PC) 828-830 as regards the tort of breach of statutory duty. Also Li Yuk Lan v Lau Kit Ling [1989] HKLR (CA) 247 [11].

82 Securities and Futures Ordinance (n 70) s 108.

83 Singapore: Financial Advisers Act (n 8), ss 25-27; UK: Financial Services and Markets Act (n 16) s 138D(2) read with Financial Services and Markets Act 2000 (Rights of Action) Regulations 2001 (ROA) reg 3(1). 
Singapore as an example, rights to proactive disclosure of accurate product information and to suitable investment recommendations are enforceable in private actions by persons who suffer loss from their breach. ${ }^{84}$ They have, however, hardly been invoked in reported cases, as pointed out by Dora Neo in Chapter 11.

1.34 There are impediments to retail investors using court litigation - it is time-consuming; the outcome is uncertain and may expose the loser to costs; it can be expensive if legal advisers are involved in the absence of a contingency arrangement; and it is procedurally and substantively complex if legal advisers are not involved. In short, 'the common law courts are not an effective place for David to take on Goliath in commercial disputes' ${ }^{85}$ It is essential, therefore, for jurisdictions to offer a more accessible alternative to the formal litigation system. Financial alternative dispute resolution (ADR) is an important subset of ADR. An international association called the International Network of Financial Services Ombudsman Schemes (INFO Network) fosters the development of sound and effective financial ADR practices. ${ }^{86}$ INFO Network subscribes to six principles for financial ADR schemes, namely 'independence, to secure impartiality; clarity of scope and powers; accessibility; effectiveness; fairness; transparency and accountability' ${ }^{87}$ These high-level principles offer a useful yardstick by which to assess a jurisdiction's financial ADR mechanisms.

1.35 The jurisdictional chapters in this volume all highlight the availability of ADR facilities designed specifically for financial disputes involving consumers. The Australian Financial Complaints Authority (AFCA) provides an ombudsman service for a wide range of disputes between financial services licence holders and eligible persons, including individuals and small businesses. A wide range of financial products is covered. AFCA's remedial jurisdiction is limited to AUD $1,085,000,{ }^{88}$ and decisions are based on what is considered to be fair in all the circumstances. ${ }^{89}$ Mediation is promoted in China as the primary dispute resolution mechanism for disputes in general, and a number of mediation services are available, including from financial sector associations such as the Securities Association of China and and the Asset Management Association of China. ${ }^{90}$ The financial ADR schemes in Hong Kong and Singapore offer a two-stage process for consumer customers of financial institutions, generally starting with consensual mediation, which can be escalated to arbitration. Hong Kong's Financial Dispute Resolution Scheme saw an expansion of its jurisdiction in 2018 to include small enterprises as eligible claimants, as well as an increase in the claimable amount from

84 Financial Advisers Act (n 8), ss 25-27. These rights are restricted, eg the disclosure requirement in s 25 applies to units in collective investment schemes and life policies; accredited investors do not qualify for the rights of disclosure in $\mathrm{s}$ 25: see Financial Advisers Regulations (n 19), Reg 33; banks are exempted from compliance with ss 25-27 in certain circumstances, see Financial Advisers (Exemption from Sections 25 to 29 and 36) Regulations (GN No S 616/2004, 2007 Revised Edition).

85 Richard Samuel 'Tools for culture change: FCA, now you are listening! Time to build an independent, low cost forum for conduct dispute resolution' (2017) 12:3 CMLJ 277, 282.

86 See INFO Network's website <www.networkfso.org/index.html> accessed 21 February 2021.

87 ibid 'About Us'.

88 Australian Financial Complaints Authority ‘Complaint Resolution Scheme Rules' 13 January 2021, p 41 <www.afca.org .au/about-afca/rules-and-guidelines> accessed 11 March 2021.

89 See Paterson, ch 8.

90 See Zhou ch 9. 
$\mathrm{HK} \$ 500,000$ to $\mathrm{HK} \$ 1,000,000 .{ }^{91}$ In Singapore, the services of the Financial Industry Disputes Resolution Centre are available to individuals and sole proprietors. ${ }^{92}$ There is no claim limit for mediation, and the claim limit for the adjudication service is SG\$100,000. The UK has the Financial Ombudsman Service, which is available to individuals and small businesses and can award up to $£ 355,000$ in compensation, an increase from the initial limit of $£ 150,000 .{ }^{93}$ It is not bound by precedent and decides cases on the basis of what it considers fair. In the US a key ADR provider is the Financial Industry Regulatory Authority, which offers an extensive mediation and arbitration service for investors with complaints against investment brokers with no claim limit. ${ }^{94}$

Aside from claim limits and eligible claimants, other points of comparison between schemes include the cost of using the service and its resources, whether legal representation is permitted, its procedure and the expertise of the presiding officers. A challenge for ADR in the investment mis-selling context is the complexity of the issues that can be raised and the suitability of ADR to address them. A quick and relatively informal process can be justified for claims of modest monetary value, notwithstanding their complexity. Increasing the jurisdiction of these schemes, however, calls into question their suitability for the task. ${ }^{95}$ On the other hand, the formal, slow and expensive court litigation system is not a viable alternative for many customers unhappy with the investment advice they have received, which raises the question whether an intermediate option is needed.

The UK offers a microcosm of this debate, having considered the establishment of a financial services tribunal to operate alongside the existing court and ombudsman options. In 2016 Richard Samuel advocated the establishment of a forum based on the UK's tribunal system in other sectors, ${ }^{96}$ namely a low-cost, specialised tribunal combining accusatorial and inquisitorial elements which would be part of the court system and capable of developing the law through binding precedent. ${ }^{97} \mathrm{~A}$ particular benefit would be responding to the needs of those investors, such as SMEs, which fall into the gap between the greater protections given to individual retail investors and the caveat emptor philosophy that applies to institutional investors. There was considerable interest in Samuel's proposal but ultimately it did not find favour with the government of the day, which opted instead to expand the jurisdiction of the Financial Ombudsman Service by increasing the claim limit and broadening the eligible claimants to include more SMEs. ${ }^{98}$ A more granular study is needed to make meaningful comparisons between vastly different jurisdictions, but it is noteworthy that China has specialist financial tribunals oper-

91 See Ding and Ho, ch 10, and the website of the Financial Dispute Resolution Centre <www.fdrc.org.hk/> accessed 21 February 2021.

92 See Neo ch 11 and the website of the Financial Industry Disputes Resolution Centre Limited <www.fidrec.com.sg/ website/index.html> accessed 21 February 2021.

93 See Stanton ch 12.

94 See Bullard ch 13 and the website of FINRA <www.finra.org/about/what-we-do> accessed 21 January 2021.

95 See Powley and Stanton (n 16) 92.

96 Such as the UK's Employment Tribunal, see <www.gov.uk/courts-tribunals/employment-tribunal> accessed 26 February 2021.

97 See Richard Samuel 'Tools for changing banking culture: FCA are you listening?' (2016) 11:2 CMLJ 129; Samuel 'Tools for culture change' (n 85); Richard Samuel 'The FCA has now listened: banks, it is in your interests to listen too' (2018) 13:1 CMLJ 3.

98 Holly Powley and Keith Stanton 'SMEs and financial services disputes: part 2: a Financial Services Tribunal (2019) 3 JIBFL 186. 
ating within its primary and intermediate court systems. ${ }^{99}$ In summary, this short discussion reinforces the need for jurisdictions to regularly review the adequacy of their dispute resolution mechanisms. Of particular value to facilitate scholarly debate is the availability of anonymised information and data on the cases handled by ADR schemes.

\section{CONCLUSION}

1.38 An investor protection framework needs a multi-pronged approach to avoid pitfalls and achieve optimal outcomes, and this volume shows jurisdictions using a combination of strategies to this end. Notwithstanding the undeniable costs of a regulatory regime - which makes investment products and services more expensive - regulation provides essential support to the private law in managing the wealth management sector. There is no escaping the need to strike the familiar but perhaps elusive balance between an overly strict regime that risks stifling the market and denying stakeholders opportunities to maximise economic wellbeing, and an overly permissive environment that is likely to be harmful not only to investors but to society and the reputation of the wealth management sector. In the same way that the prudential regulatory framework for financial institutions does not seek to prevent all failures, investor protection frameworks cannot avoid all investment ills. Nevertheless, a carefully calibrated, well-monitored, enforced and enforceable framework, sensitive to the needs of the stakeholders and alert to the inevitable evolution of the sector, can realise the goal of welfare maximisation. 